
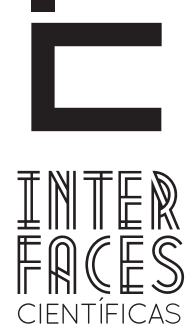

DIREITO

ISSN IMPRESSO 2316-3321

ISSN ELETRÔNICO 2316-381X

DOI 10.17564/2316-381X.2015v4n1p11-22

\title{
A APLICAÇÃO DA TEORIA DO DESESTIMULO COMO FORMA DE INIBIÇÃO DA RESPONSABILIDADE CIVIL NO BRASIL
}

George Carvalho ${ }^{1}$

\section{RESUMO}

0 presente artigo traz um estudo detalhado sobre a aplicação da teoria do desestimulo como uma forma de inibir a responsabilidade civil no ordenamento jurídico pátrio. No decorrer da presente pesquisa aborda-se a definição da responsabilidade civil, além dos seus pressupostos e espécies, bem como o conceito de teoria do desestimulo, sua origem e possíveis críticas ao seu respeito. 0 grande problema, enfrentado no presente artigo, diz respeito à utilização da teoria do desestimulo no direito brasileiro. A par dos posicionamentos doutrinários e jurisprudenciais sobre 0 tema, verifica-se que a teoria encontra-se em harmonia com os direitos fundamentais, sendo perfeitamente cabível a sua aplicação.

\section{PALAVRAS-CHAVE}

Responsabilidade Civil. Teoria Desestimulo. Brasil. 


\section{ABSTRACT}

This article offers a detailed study on the implementation of disincentive theory as a way to inhibit the liability in Brazilian legal system. In the course of this research addresses the definition of liability, in addition to its assumptions and species as well as the concept of theory disincentive, its origin and possible criticism of him. The major problem faced in this article relates to the use of disincentive theory in Brazilian law. In addition to the doctrinal and jurisprudential positions on the subject, it appears that the theory is in harmony with fundamental rights, and perfectly fitting your application.

\section{KEYWORDS}

Civil Responsability. Disincentive Theory. Brazil.

\section{RESUMEN}

En este trabajo se presenta un estudio detallado sobre la aplicación de la teoría del desincentivo como una forma de inhibir la responsabilidad civil en el sistema jurídico brasileño. En el curso de esta investigación se aborda la definición de la responsabilidad civil, además de sus supuestos y especies, así como el concepto de teoría del desincentivo, su origen y las posibles críticas a su respecto. El principal problema enfrentado en este artículo se refiere al uso de la teoría del desincentivo

en la legislación brasileña. Aclarados de las posiciones doctrinales y jurisprudenciales sobre el tema, nos parece que la teoría está en armonía con los derechos fundamentales, siendo perfectamente aplicable.

\section{PALABRAS CLAVE}

Responsabilidad civil. Teoría del desincentivo. Brasil. 


\section{INTRODUÇ̄̃O}

A responsabilidade civil é um fator determinante para se garantir a reparação de um eventual dano, decorrente de um ato lesivo. Todavia, para que se tenha uma condenação baseada na responsabilidade civil, se faz necessário a comprovação dos seus pressupostos, quais sejam, ação ou omissão, dolo ou culpa, relação de causalidade e dano.

Assim, a responsabilidade civil pode ser observada de varias formas, ou seja, é dividida por espécies, quanto ao seu fato gerador, quanto ao fundamento e quanto ao agente. Os quais também serão objeto de estudo.

No que tange as penalidades aplicadas a titulo de indenização por dano moral, observa-se um caráter compensatório. Entretanto, após a origem da teoria do desestimulo, buscou-se uma penalidade com caráter preventivo e punitivo, como uma forma de evitar que o ofensor cometesse o mesmo ato lesivo reiteradamente.

A teoria do desestimulo teve origem nos Estados Unidos da América, e sofreu algumas criticas quando passou a ser usada no direito brasileiro, tendo em vista que as penalidades aplicadas naquele país eram muitas vezes milionárias; o que acabava gerando uma insegurança e caracterizando enriquecimento ilícito, o que não é permitido no ordenamento jurídico brasileiro.

Por fim, no presente artigo será analisada a aplicabilidade da teoria do desestimulo no direito brasileiro, tentando esclarecer o seu caráter dúplice, bem como posicionamentos sobre o tema e a sua eficácia.

\section{RESPONSABILIDADE CIVIL - CONCEITO}

Antes de se verificar o conceito de responsabilidade civil, faz-se necessário analisar o significado de responsabilidade, o que de certa forma acaba contribuindo para o referido conceito. 0 termo responsabilidade refere-se à obrigação de se responder por determinado ato praticado, ou seja, uma imposição decorrente de algum ato.

Segundo Venosa (2010, p. 1),
O termo responsabilidade é utilizado em qualquer situação na qual alguma pessoa, natural ou jurídica, deva arcar com as conseqüências de um ato, fato ou negócio danoso. Sob essa noção, toda atividade humana, portanto, pode acarretar o dever de indenizar.

Dessa forma, verifica-se que o termo responsabilidade não se resume apenas na obrigação de quem causou o dano de repará-lo, mas também em garantir uma relação jurídica equilibrada e ética. Deve-se ressaltar que a responsabilidade existe em vários ramos do Direito, como penal, administrativo, trabalhista etc.

Com isso denota-se que a responsabilidade civil esta relacionada à ideia de não prejudicar o outro, devendo assim reparar o dano, independentemente de culpa, nos casos especificados em lei, ou quando a atividade normalmente desenvolvida pelo autor do dano implicar, por sua natureza, risco para os direitos de outrem.

Para Maria Helena Diniz (2007, p. 34), responsabilidade civil pode ser definida:

[...] a aplicação de medidas que obriguem alguém a reparar dano moral ou patrimonial causado a terceiros em razão de ato do próprio imputado, de pessoa por quem ele responde, ou de fato de coisa ou animal sob sua guarda ou, ainda, de simples imposição legal.

Esclarece-se ainda que o conceito acima citado é norteado pela culpa, sendo este um dos elementos da responsabilidade civil.

\subsection{PRESSUPOSTOS}

Os pressupostos da responsabilidade civil podem ser observados no art. 186 do CC "Aquele que, por ação ou omissão voluntaria, negligência ou imprudência, violar direito e causar dano a outrem, ainda que exclusivamente moral, comete ato ilícito".

Conforme exposto acima se verifica que são quatro os elementos essenciais da responsabilidade civil: ação ou omissão, culpa ou dolo do agente, relação de causalidade e o dano sofrido pela vitima, os quais veremos a seguir.

A ação ou omissão refere-se a qualquer pessoa que 
por determinado ato venha a causar dano a outrem, seja este por meio de uma ação ou omissão. Sendo que a responsabilidade pode derivar de ato próprio, ato de terceiro que esteja sob a guarda do agente, e por fim danos causados por coisas ou animais que the pertençam.

Na culpa ou dolo, ambos estão relacionados à vontade do agente, entretanto no dolo existe a intenção de violar o direito, é uma vontade deliberada e consciente. Enquanto que na culpa, a vontade é retratada por meio da negligência, e não se tem intenção de cometer determinado ato. Neste caso para que haja a reparação é necessário se comprovar o dolo ou culpa.

De acordo com Cahali (2002, p. 810),

[...] em sede indenizatória por danos patrimonial e moral, mesmo levando-se em conta a teoria da distribuição do ônus da prova, a cabência desta está ao encargo do autor a provar o nexo causal constituidor da obrigação ressarcitória, pois, inexistindo causalidade jurídica, ausente está a relação de causa e efeito, mesmo porque actore non probante, réus absolvitur.

A relação de causalidade esta ligada a relação de causa e efeito entre a ação ou omissão do agente e o dano verificado. É preciso que o dano tenha ocorrido em decorrência do comportamento do agente, pois em que pese se ter o dano, mas se não tiver esta ligação, deixa de existir a obrigação de indenizar.

Quanto ao dano, o mesmo precisa ser provado, pois sem prova ninguém pode ser responsabilizado. Podendo ser o dano material ou simplesmente moral, ou seja, que não tenha repercutido na situação financeira do ofendido.

Para Sérgio Cavalieri Filho (APUD MENDES, 2000, p. 157),

O ressarcimento do dano moral tem uma genérica função satisfatória, com a qual se procura um bem que recompense, de certo modo, o sofrimento ou a humilhação sofrida. Substitui-se o conceito equivalência, próprio do dano material, pelo de compensação, que se obtém atenuando, de maneira indireta, as conseqüências do sofrimento.

Ademais, pode-se dizer que o dano moral é uma forma compensatória ao sofrimento, vexame passado pela vítima, como meio de amenizar o transtorno e não uma forma de pagamento.

\subsection{ESPÉCIES}

As espécies de responsabilidade civil podem ser apresentadas quanto ao seu fato gerador, quanto ao fundamento e quanto ao agente.

Quanto ao seu fato gerador é dividida em responsabilidade contratual e extracontratual ou aquiliana. A responsabilidade contratual incide quando ocorre o descumprimento total ou parcial de uma relação contratual. Cabendo ao devedor o ônus de provar que não houve culpa da sua parte ou qualquer excludente do dever de indenizar. Na responsabilidade extracontratual ou aquiliana quando uma pessoa causa dano a outra por meio de um ato ilícito, conforme disposto no art. 927 do CC.

Quanto ao fundamento é dividida em responsabilidade subjetiva e objetiva. Na responsabilidade subjetiva é indispensável a comprovação da culpa do agente do ato ilícito, caso contrario, não se pode caracterizar o dever de indenizar. Já a responsabilidade objetiva encontra respaldo na teoria do risco, ou seja, quando a atividade desenvolvida pelo autor do dano, for capaz de causar danos a outrem. Ressalta-se que neste caso não há necessidade de se comprovar culpa, basta a ocorrência do ato ilícito.

Por fim a responsabilidade quanto ao agente que pode ser direita ou indireta. A direta é quando o dano é ocasionado pelo próprio agente, devendo responder por seus próprios atos. A indireta é quando o dano ocorre em decorrência de um ato de terceiro, o qual o agente é o responsável, seja de animal ou coisas sob sua guarda.

\section{DANO MORAL}

A Constituição da República Federativa do Brasil de 1988, em seu artigo 50, incisos V e X, preceitua a possibilidade de indenização por danos morais e materiais, o que o faz nos seguintes termos, ex vi: 
Art. $5^{\circ},[\ldots]$

$V$ - é assegurado o direito de resposta, proporcional ao agravo, além da indenização por dano material, moral ou à imagem:

[...]

X - são invioláveis a intimidade, a vida privada, a honra e a imagem das pessoas, assegurado o direito a indenização pelo dano material ou moral decorrente de sua violação.

Nesse mesmo sentido, disciplina o Código Civil de 2002, conforme dispõem os seus artigos 186, 187 e 927, abaixo transcritos:

Art. 186. Aquele que, por ação ou omissão voluntária, negligência ou imprudência, violar direito e causar dano a outrem, ainda que exclusivamente moral, comete ato ilícito.

Art. 187. Também comete ato ilícito o titular de um direito que, ao exercê-lo, excede manifestamente os limites impostos pelo seu fim econômico ou social, pela boa-fé ou pelos bons costumes.

Art. 927. Aquele que, por ato ilícito, causar dano a outrem, fica obrigado a repará-lo.

O Ilustre doutrinador Cahali (2002, p. 20) diz que o dano moral,

[...] é a privação ou diminuição daqueles bens que têm um valor precípuo na vida do homem e que são a paz, a tranqüilidade de espírito, a liberdade individual, a integridade individual, a integridade física, a honra e os demais sagrados afetos, classificando-se desse modo, em dano que afeta a parte social do patrimônio moral(honra, reputação, etc.) e dano que molesta a parte afetiva do patrimônio moral (dor, tristeza, saudade, etc.), dano moral que provoca direta ou indiretamente dano patrimonial (cicatriz deformante, etc.) e dano moral puro (dor, tristeza, etc.).

Já para Bittar, "são morais os danos e atributos valorativos (virtudes) da pessoa como ente social, ou seja, integrada à sociedade (como, v.g., a honra, a reputação e as manifestações do intelecto)" (BITTAR, 1993, p. 24)

Cumpre observar, que grande parte da doutrina nacional, entende, em linhas gerais, que a condenação em dinheiro serve apenas como uma compensação financeira aos prejuízos, dores e sofrimentos experimentados pela vítima, tendo esta condenação um caráter punitivo ao lesante. Desse modo, não há que se falar em enriquecimento ilícito da vitima, já que não a indenização tem um caráter reparatório.

\section{TEORIA DO DESESTIMULO - CONCEITO}

A teoria do desestimulo é utilizada no caso de um ato lesivo, provocar danos seja na esfera moral ou material, momento em que terá que pagar uma determinada quantia a ser arbitrada pelo magistrado a titulo de punição, como uma forma de tal conduta não voltar a acontecer.

Segundo a teoria do desestímulo, a indenização deve ter função dúplice, prestando tanto para uma compensação pelos sentimentos negativos suportados pela promovente (caráter compensatório), quanto servindo de punição pela conduta desenvolvida pelo agente lesivo (caráter punitivo).

Deste modo, para que atenda a sua dupla finalidade, o montante indenizatório deve ser fixado em quantum que, além de abrandar o menoscabo moral sofrido pela vítima lesada em seus direitos básicos, tenha o condão de desestimular o agente lesivo a praticar novamente a mesma conduta.

Delgado (2011a, p. 306) dispõe que,

\begin{abstract}
A teoria do Valor do Desestimulo é um instituto que através da condenação a uma soma milionária, pretende obter, a um só tempo, a punição do ofensor, desestimulando-o a reincidir no erro e proporcionar um exemplo á sociedade, como meio preventivo e profilático.
\end{abstract}

Assim, pode-se dizer que a teoria do desestimulo fundamenta-se no binômio: punição x prevenção. Santos (2003, p. 162) segue na mesma linha:

A indenização do dano moral, além do caráter ressarcitório, deve servir como sanção exemplar. A determinação do montante indenizatório deve ser fixado tendo em vista a gravidade objetiva do dano causado e a repercussão que o dano teve na vida do prejudicado, o valor que faça com que o ofensor se evada de novas indenizações, evitando outras infrações danosas.

Desta forma, indenização proveniente do dano moral tem como finalidade precípua de coibir práticas reiteradas na sociedade. 


\subsection{ORIGEM}

A teoria do desestimulo teve origem nos Estados Unidos da América sob o nome de teoria dos punitive damages, visando aplicar uma punição para que 0 agressor não venha a cometer novamente atos lesivos ao patrimônio moral das pessoas.

Em pese que ter surgido nos Estados Unidos da América, a teoria do desestimulo, como foi denominada no Brasil, acaba não sendo aplicada da mesma forma, tendo em vista que naquele país as indenizações são muitas vezes milionárias, enquanto que no Brasil são pequenas e às vezes até irrisórias, o que acaba estimulando o lesante a cometer a mesma conduta diversas vezes.

Ocorre que a teoria do desestimulo não foi originada simplesmente para compensar ou ressarcir danos morais ou materiais, mas sim com o intuito preventivo, para que não haja a reincidência de atos lesivos, ficando assim como uma forma de exemplo para toda a sociedade.

Dessa forma percebe-se que a teoria do desestimulo não possui um caráter compensatório, nem ressarcitório, sendo esta a função dos danos morais e materiais, mas sim pedagógico, procurando desestimular o ofensor a não praticar reiteradamente atos que lesionem o patrimônio seja moral ou patrimonial de uma pessoa.

\subsection{CRIITICAS}

Conforme exposto no tópico acima, a teoria do desestímulo surgiu nos Estados Unidos da América e em seguida passou a ser utilizada no Brasil. Todavia, alguns doutrinadores criticam a referida teoria aplicada naquele país, tendo em vista que se trata de indenizações com valores extremamente exorbitantes.

Isso de certa forma acabou gerando certa instabilidade na sociedade, uma vez que as pessoas passaram a sentir medo de serem processadas e terem que pagar indenizações absurdas.

Delgado (APUD MARÇAL, 2011b, p. 309) afirma que:
Vemos diariamente na imprensa casos ocorridos nos EUA, como o de pais que se recusam a receber, em suas residências, colegas de seus filhos sem que estes portem termos que os isente de responsabilidade por qualquer acidente que eventualmente ocorra durante o dia. Escolas se recusam a dar uma aspirina para um estudante, com receio de que este tenha uma crise alérgica.

Dessa forma as indenizações por danos morais e materiais provenientes da teoria do desestimulo, acaba possuindo um caráter punitivo e não apenas compensatório.

Ressalta-se que após a implantação da teoria do desestimulo, passou-se a ter um aumento considerável de ações junto ao poder judiciário com o objetivo de se auferir indenizações de certa forma milionárias, o que acabou gerando uma espécie de estimulo a ganhar muito dinheiro de forma "fácil".

\section{APLICABILIDADE DA TEORIA DO DESESTIMULO NO DIREITO BRASILEIRO}

A aplicação da teoria do desestimulo no direito brasileiro possui algumas controvérsias quanto à aplicada nos Estados Unidos da América.

No direito norte americano as indenizações por danos morais e materiais, oriunda da teoria do desestimulo, tem como característica a aplicação de valores exorbitantes, justamente com o intuito de evitar que ações semelhantes possam acontecer posteriormente.

Por outro lado, o ordenamento jurídico brasileiro não permite que sejam aplicadas penalidades de caráter milionário, e, por conseguinte às vezes acaba não surtindo o mesmo efeito.

Nesse sentido é colocado não ser valida a aplicação da teoria no direito brasileiro, sob a argumentação de não ser permitido o enriquecimento ilícito, conforme disposto no artigo 884 do CC.

Todavia, aquela não parece ser o entendimento mais aceitado, vez que a aplicação da teoria norte americana acaba concretizando os direitos constitucionais do consumidor, bem como do reclamante na relação trabalhista, dentre outras relações. Isto faz com que além 
das vitimas receberem as indenizações, os ofensores se abstenham de cometer novamente atos lesivos.

A indenização com caráter punitiva não possui respaldo no ordenamento jurídico brasileiro, e a sua aplicação estaria ofendendo a garantia constitucional consubstanciada no art. $5^{\circ}, \mathrm{XXXIX}$, da CF, “Não há crime sem lei anterior que o defina, nem pena sem previa cominação legal”.

É certo que a regra que prevalece na responsabilidade civil, é a disposta no art. 944 do CC, "A indenização mede-se pela extensão do dano. Parágrafo Único - se houver excessiva desproporção entre a gravidade da culpa e o dano, poderá o juiz reduzir, equitativamente, a indenização".

Todavia, após uma análise detalhada do referido artigo, percebe-se que há uma preocupação quanto à quantificação do montante a ser aplicado ao ofensor, o que muitas vezes não é suficiente para compensar 0 ato lesivo.

Ressalta-se que o artigo não faz menção sobre a possibilidade de se majorar o valor indenizatório, pelo contrario, a vítima pode acabar recebendo valores inferiores ao prejuízo obtido.

Entretanto, para o doutrinador André Gustavo Corrêa de Andrade (2009, p. 237) a indenização punitiva possui respaldo no ordenamento jurídico brasileiro, através da Constituição Federal de 1988, ele esclarece que:

É no princípio da dignidade humana, estabelecido no art. $1^{\circ}$, inciso III, da Constituição Federal, que a indenização punitiva encontra sua base lógico-jurídica. A aplicação dessa forma especial de sanção constitui, também, consectário lógico do reconhecimento constitucional dos direitos da personalidade e do direito à indenização do dano moral, encartados no art. $5^{\circ}$, incisos V e X, da Constituição brasileira.

Assim, a aplicação da teoria do desestímulo é uma forma de garantir a efetividade da dignidade da pessoa humana e aos princípios personalíssimos, por meio do caráter de punição e prevenção disposto na teoria.

Importante defensor da aplicação da teoria do desestímulo no Brasil é Bittar (2001, p. 114), o qual preleciona que,

Adotada a reparação pecuniária - que, aliás é a regra na prática, diante dos antecedentes expostos -, vem-se cristalizando orientação na jurisprudência nacional que, já de longo tempo, domina o cenário indenizatório nos direitos norte-americanos e inglês. É a da fixação de valor que serve como desestímulo a novas agressões, coerente com o espírito dos referidos punitive ou exemplary damages da jurisprudência daqueles países. Em consonância com essa diretriz, a indenização por danos morais deve traduzir-se em montante que represente advertência ao lesante e à sociedade de que não se aceita o comportamento assumido, ou o evento lesivo advindo. Consubstancia-se, portanto, em importância compatível com o vulto dos interesses em conflito, refletindo-se de modo expressivo, no patrimônio do lesante, a fim de que sinta, efetivamente, a resposta da ordem jurídica aos efeitos do resultado lesivo produzido. Deve, pois, ser quantia economicamente significativa, em razão das potencialidades do patrimônio do lesante.

No caso concreto, a aplicação das indenizações punitivas se divide entre os Tribunais, e as divergências sobre os valores acabam no Superior Tribunal de Justiça, que atua no sentido de reformar, seja quando aplicado um valor intimo ou exagerado.

Diante do exposto, vejamos o posicionamento do Tribunal de Justiça de Santa Catarina a respeito do tema:

APELAÇÃO CÍVEL. AÇÃO DE INDENIZAÇÃO POR DANO MORAL COM PEDIDO LIMINAR. INSCRIÇÃO INDEVIDA NOS ÓRGÃOS DE PROTEÇÃO AO CRÉDITO. CESSÃO DE CRÉDITO E EXISTÊNCIA DO DÉBITO NÃO COMPROVADOS. APELAÇÃO DA EMPRESA RÉ. AFASTADA ILEGITIMIDADE PASSIVA. DEVER DE INDENIZAR. DANO MORAL PRESUMÍVEL. RELAÇÃO JURÍDICA COMPROVADA. VALOR INDENIZATÓRIO MANTIDO. APLICAÇÃO DA TEORIA DO DESESTÍMULO. RECURSO CONHECIDO E IMPROVIDO.

A inscrição do nome de qualquer pessoa em cadastro negativo de proteção de crédito, sem lastro em transação comercial ou prestação de serviço, gera reparação in reipsa, sem necessidade de comprovação do abalo sofrido porquanto este decorre da inscrição ilícita. (AC 20120407380 SC 2012.040738-0 (Acórdão), Relator(a): Saul Steil, Julgamento: 13/08/2012,Órgão Julgador: Terceira Câmara de Direito Civil Julgado).

Observa-se no julgado acima que é cabível a indenização por dano moral sempre que houver a materialização da ofensa, ainda que decorrente da ausência de prejuízo. 
No mesmo sentido aduz o Tribunal de Justiça da Bahia e o Tribunal de Justiça de São Paulo, proferindo decisões pautadas na teoria do desestímulo, vejamos:

PROCESSUAL CIVIL E DIREITO DO CONSUMIDOR. AÇÃO INDENIZATÓRIA POR DANOS MORAIS CUMULADA COM OBRIGAÇÃO DE FAZER JULGADA PARCIALMENTE PROCEDENTE. RECURSO DE APELAÇÃO.

[...] grau de culpa do agente, terceiro ou da vítima (arts. 944 e 955, do CC ); aspectos psicológicos dos envolvidos; finalidade da sanção reparatória; emprego dos princípios da razoabilidade e proporcionalidade; e a aplicação da teoria do desestímulo; Assim, não merece prosperar o requerimento do Apelante para a redução da verba indenizatória, posto que cotejando os critérios acima enumerados a indenização fixada em $\mathrm{R} \$ 5.000,00$ (cinco mil reais) revela-se adequada às circunstâncias fáticas apuradas na lide; Por fim, não merece prosperar o pedido de redução dos honorários advocatícios, calcado no $\S 1^{\circ}$, do art. 11 , da Lei $1.060 / 50$, pois, apesar da redação do referido dispositivo, a jurisprudência pátria reconhece a possibilidade de fixação de honorários sucumbenciais superiores a quinze por cento; Ademais, os honorários de vinte por cento, arbitrados pela sentença de piso, importam, tão somente em um mil reais, quantia que se mostra adequada, nos termos do $\S 3^{\circ}$, do art. 20 , do CPC , à remuneração dos serviços prestados pelos advogados do Autor. RECURSO CONHECIDO E IMPROVIDO. (Processo: APL 00007484920098050245 BA 0000748-49.2009.8.05.0245, Julgamento: 10/02/2014, Órgão Julgador: Primeira Câmara Cível, Publicação: 12/02/2014).

RESPONSABILIDADE CIVIL Dano moral Pagamento da fatura de telefone fixo com antecedência devido à greve Ainda assim houve cobrança, cancelamento da linha e negativação do nome da apelada Negligência Inacolhíveis as ponderações e postulações do recurso - Conduta do recorrente traduz a ocorrência de danos morais "in re ipsa"- Impossibilidade de fixação do "quantum" em salários mínimos Indenização fixada em R\$ 10.900,00 - Aplicação da teoria do valor do desestímulo para a definição do "quantum" indenizatório Recurso não provido. (TJ-SP - APL: 00081143920098260445 SP $0008114-$ 39.2009.8.26.0445, Relator: Marcia Dalla Déa Barone, Data de Julgamento: 26/03/2014, $14^{\text {a }}$ Câmara de Direito Privado, Data de Publicação: 27/03/2014).

Nota-se que a aplicação da teoria do desestímulo é pautada nos princípios da razoabilidade e proporcio- nalidade, com o escopo de manter um equilíbrio entre o fato ocorrido e o ressarcimento pelo dano, evitando um enriquecimento ilícito.

Comumente os Tribunais vêm condenando as instituições financeiras ao pagamento de indenizações mais elevadas, levando-se em consideração a teoria do desestímulo. Nesse sentido, julgado abaixo vazado do Tribunal de Justiça da Bahia,

APELAÇÃO CÍVEL. DEVOLUÇÃO DE CHEQUE. COMPENSAÇÃO REALIZADA. ALEGAÇÃO DE FURTO/ROUBO DE MALOTE. FALHA NA PRESTAÇÃO DO SERVIÇO. DIREITO DO CONSUMIDOR. RESPONSABILIDADE OBJETIVA. DANO MORAL CONFIGURADO. DEVER DE INDENIZAR. QUANTIFICAÇÃO. R\$ 12.000,00. VALOR CONDIZENTE. TEORIA DO DESESTÍMULO. AUSÊNCIA DE EXAGERO. DANO MATERIAL. PAGAMENTO DE JUROS POR PARTE DO APELADO. DEMONSTRAÇÃO. VALOR R\$ 509,26. PAGAMENTO DECORRENTE DA PRESTAÇÃO FALHA DOS SERVIÇOS. DANO MATERIAL CONFIGURADO. APELO DESPROVIDO. SENTENÇA MANTIDA. - Ante a aplicação do CDC, não há que se falar em análise de culpa, posto que a responsabilidade incidente, neste caso, é objetiva. Sendo assim, recai sobre o apelante o dever de indenizar pelo fato de devolver cheque devidamente compensado, e com provisão de fundos, sob o errôneo argumento de furto/roubo de malote. - Encontrando-se condizente o montante fixado com os parâmetros utilizados pela jurisprudência para casos como o presente e fomentando, ainda, a sustentação da teoria do desestímulo, o pleito do Banco apelante quanto à redução do valor a título de danos morais não deve ser atendido. - Não incide no presente caso a regra do art. 944, do Código Civil, já que, quando se fala em dano moral, não há como mensurar a extensão do dano provocado pela conduta ofensiva. - Por fim, quanto ao dano material, restou comprovado que o Apelado sofreu prejuízo de R\$ 509,26, resultante da cobrança de juros, em decorrência da má prestação dos serviços por parte do Apelante, o que deixa evidente a configuração de conduta danosa. - Apelo improvido. - Sentença mantida intacta. (TJ-BA - APL: 00000865420128050189 BA 0000086-54.2012.8.05.0189, Data de Julgamento: 17/12/2013, Quarta Câmara Cível, Data de Publicação: 18/12/2013).

No tocante ao STJ, em que pese se declarar adepto a teoria utilizada com a função punitiva, muitas vezes acaba atuando no sentido de reduzir as indenizações 
fixadas pelos Tribunais de Justiça. Na maioria das suas decisões, utiliza-se dos princípios da razoabilidade e da proporcionalidade para estabelecer o quantum indenizatório,

PROCESSUAL CIVIL E ADMINISTRATIVO. AGRAVO EM RECURSO ESPECIAL. AÇÃO DE INDENIZAÇÃO POR DANOS MORAIS E MATERIAIS. ENERGIA ELÉTRICA. INTERRUPÇÃO NO FORNECIMENTO DOS SERVIÇOS POR FALTA DE PAGAMENTO. CONTAS INADIMPLIDAS. AUSÊNCIA. COMUNICAÇÃO PRÉVIA ACERCA DA POSSIBILIDADE DE CORTE. INOCORRÊNCIA. DEMORA INJUSTIFICADA NO RESTABELECIMENTO DOS SERVIÇOS. DANO MORAL. CONFIGURADO. QUANTUM INDENIZATÓRIO. RAZOABILIDADE E PROPORCIONALIDADE. REEXAME DE PROVAS. SÚMULA 7/STJ. 1. A jurisprudência do Superior Tribunal de Justiça é firme no sentido de admitir o reexame da fixação da reparação a título de danos morais somente na hipótese de determinação de quantia exorbitante ou irrisória. 2. Quando o valor estabelecido estiver adequado aos parâmetros de proporcionalidade e razoabilidade, é inviável a alteração do quantum, por demandar, necessariamente, o revolvimento do suporte fático-probatório dos autos, o que é vedado pelo óbice da Súmula 7/STJ. Precedentes. 3. Agravo regimental não provido.

(STJ - AgRg no AREsp: 354180 PE 2013/0181124-7, Relator: Ministra ELIANA CALMON, Data de Julgamento: 05/09/2013, T2 - SEGUNDA TURMA, Data de Publicação: DJe 17/09/2013).

Em diversos julgados, o STJ acaba por fulminar a teoria do desestímulo, pois fixa valores máximos que podem ser recebidos de acordo com o dano. Nesse sentido, fixou o valor para o dano proveniente da recusa em cobrir tratamento médico-hospitalar (sem dano à saúde) em $\mathrm{R} \$ 20.000,00^{2}$; o valor do dano proveniente da recusa em fornecer medicamento (sem dano à saúde) em 10 vezes o salário mínimo ${ }^{3}$; o valor do dano proveniente do cancelamento injustificado de vôo em R\$ 8.000,004; inexistência de valor a indenizar no caso de compra de veículo com defeito de fabricação, tendo sido o problema resolvido dentro da garantia ${ }^{5}$; 2. STJ - REsp 986947, Relator: Ministra NANCY ANDRIGHI, T3 - TERCEIRA TURMA, em 11/03/2008.

3. STJ - REsp 801181, Relator: Ministro FERNANDO GONÇALVES, Data de Julgamento: 05/05/2009, T4 - QUARTA TURMA.

4. STJ - REsp 740968, Relator: Ministro ALDIR PASSARINHO JUNIOR, Data de Julgamento: 11/09/2007, T4 - QUARTA TURMA

5. STJ - Resp 750735, Relator: Ministro ALDIR PASSARINHO JUNIOR, Data o valor do dano proveniente da inscrição indevida em cadastro de inadimplente em $\mathrm{R} \$ 10.000,00^{6}$; o valor do dano proveniente da revista íntima abusiva em 50 vezes o salário mínimo?.

O STJ fixou, também, o valor para do dano proveniente da omissão da esposa ao marido sobre a verdadeira paternidade biológica das filhas em R\$ 200.000,008; ${ }^{9}$; o valor do dano proveniente da morte após cirurgia de amígdalas em R\$200.000,0010; o valor do dano proveniente de erro médico, ocasionando o estado vegetativo do paciente em $\mathrm{R} \$ 360.000,00^{11}$; o valor do dano proveniente do estupro em prédio público em $\mathrm{R} \$ 52.000,00^{12}$; o valor do dano proveniente da Publicação de notícia inverídica em $\mathrm{R} \$ 20.750,00^{13}$ e o valor do dano correspondente à prisão equivocada em $\mathrm{R} \$ 100.000,00^{14}$.

Por fim, é imperioso colocar a existência do projeto de Lei n $276 / 2007$, elaborado pelo deputado Leonardo Alcântara, que altera o artigo 944 do Código Civil de 2002, passando a dispor da seguinte forma:

\section{Art.944 [...]}

$\S 1^{\circ}$ Se houver excessiva desproporção entre a gravidade da culpa e o dano, poderá o juiz reduzir, equitativamente, a indenização;

$\S 2^{\circ} \mathrm{A}$ reparação do dano moral deve constituir-se em compensação ao lesado e adequado desestímulo ao lesante. (NR) (BRASIL, 2010).

de Julgamento: 04/06/2009, T4 - QUARTA TURMA.

6. STJ - REsp: 1105974 BA 2008/0260489-7, Relator: Ministro SIDNEI BENETI, Data de Julgamento: 23/04/2009, T3 - TERCEIRA TURMA, Data de Publicação: DJe 13/05/2009.

7. STJ - REsp: 856360 AC 2006/0118205-0, Relator: Ministra ELIANA CALMON, Data de Julgamento: 19/08/2008, T2 - SEGUNDA TURMA, Data de Publicação: DJe 23/09/2008.

8. STJ - REsp: 742137 RJ 2005/0060295-2, Relator: Ministra NANCY ANDRIGHI, Data de Julgamento: 21/08/2007, T3 - TERCEIRA TURMA, Data de Publicação: DJ 29/10/2007 p. 218.

9. STJ - REsp: 856360 AC 2006/0118205-0, Relator: Ministra ELIANA CALMON, Data de Julgamento: 19/08/2008, T2 - SEGUNDA TURMA, Data de Publicação: DJe 23/09/2008.

10. STJ - REsp: 1074251 SP 2008/0141463-3, Relator: Ministro SIDNEI BENETI, Data de Julgamento: 23/04/2009, T3 - TERCEIRA TURMA, Data de Publicação: DJe 15/05/2009.

11. AgRg no Ag 853854/RJ, Rel. Ministra DENISE ARRUDA, PRIMEIRA TURMA, julgado em 05/06/2007, DJ 29/06/2007, p. 504.

12. STJ - REsp 1060856 RJ, Relator: Ministro HUMBERTO MARTINS, Data de Julgamento: 23/06/2009, T2 - SEGUNDA TURMA.

13. STJ - REsp 401358 PB, Relator: Ministro CARLOS FERNANDO MATHIAS, Data de Julgamento: 05/03/2009, T2 - QUARTA TURMA.

14. STJ - Resp 872630 , Relator: Ministro FRANCISCO FALCÃO, Data de Julgamento: 13/11/2007, T1 - PRIMEIRA TURMA. 
Caso seja aprovada, sancionada e promulgada a inclusão do $\S 2^{\circ}$ no referido artigo, se terá de forma expressa a inclusão da indenização punitiva no ordenamento jurídico brasileiro.

\section{CONSIDERAÇÕES FINAIS}

Discorreu-se no presente artigo, de forma sintética e objetiva, as diversas características da responsabilidade civil. Partiu-se de uma análise desde o seu conceito, bem como os seus requisitos e espécies.

Conforme exposto no decorrer do trabalho, a responsabilidade civil encontra respaldo no Código Civil Brasileiro, por outro lado após o surgimento da teoria do desestímulo, a mesma passou a ser utilizada por operadores do direito, como forma de parâmetro para aplicação das penalidades.

A teoria do desestímulo foi importada do direito norte americano, tornando-se atualmente bastante relevante para o direito brasileiro, uma vez que a teoria está em consonância com os direitos fundamentais, buscando-se garantir uma maior efetividade quanto à responsabilidade civil do causador do dano.

O Poder Judiciário brasileiro, com parcimônia, vem reiteradamente utilizando-se da teoria do desestímulo para fixar o quantum indenizatório das condenações, de modo a desestimular novas condutas.

A teoria do desestímulo, conforme demonstrado possui um caráter preventivo e punitivo, pois a sua maior finalidade é evitar o cometimento de atos lesivos corriqueiramente. Em que pese algumas críticas quando da sua aplicação no direito brasileiro, sob a alegação de estar se caracterizando enriquecimento ilícito, restou evidenciado que tais alegações são infundadas, pois o objetivo da teoria não é promover milionárias indenizações, mas sim impedir a prática reiterada de ilicitudes civis causadoras de danos a terceiros.

Por fim, denota-se que a teoria do desestímulo deve ser aplicada com cautela, em conjugação de diversos outros critérios (equidade, extensão do dano, condição econômica do infrator etc.), de modo a se determinar uma indenização que esteja em equilíbrio entre o justo valor devido e valor que venha a servir de desestímulo ao infrator, para que iniba novas condutas ilícitas, sem enriquecer consideravelmente a vitima.

\section{REFERÊNCIAS}

ANDRADE, André Gustavo Corrêa de. Dano Moral e Indenização Punitiva: os punitive damages na experiência do common law e na perspectiva do direito brasileiro. 2.ed. atual. ampl. Rio de Janeiro: Lúmen Júris, 2009.

\section{BAHIA. Processo: APL 00007484920098050245}

BA, 0000748-49.2009.8.05.0245, Julgamento: 10/2/2014, Órgão Julgador: Primeira Câmara Cível, Publicação: 12/02/2014.

\section{BAHIA. Processo: APL 00000865420128050189 BA} 0000086-54.2012.8.05.0189, Data de Julgamento: 17/12/2013, Quarta Câmara Cível, Data de Publicação: 18/12/2013.

BITTAR, Carlos Alberto. Responsabilidade Civil. Teoria e Prática. 4.ed. Rio de Janeiro: Forense Universitária, 2001.

\section{BITTAR, Carlos Alberto. Tutela dos Direitos da Perso- nalidade e dos Direitos Autorais nas Atividades Em- presariais. São Paulo: Revista dos Tribunais, 1993.}

\section{BRASIL. Superior Tribunal de Justiça. AgRg no}

AREsp: 354180 PE 2013/0181124-7, Relator: Ministra ELIANA CALMON, Data de Julgamento: 5/9/2013, T2 - SEGUNDA TURMA, Data de Publicação: DJe $17 / 9 / 2013$.

BRASIL. Superior Tribunal de Justiça - REsp 986947 , Relator: Ministra NANCY ANDRIGHI, T3 - TERCEIRA TURMA, em 11/3/2008.

BRASIL. Superior Tribunal de Justiça - REsp 801181, Relator: Ministro FERNANDO GONÇALVES, Data de Julgamento: 5/5/2009, T4 - QUARTA TURMA. 
BRASIL. Superior Tribunal de Justiça - REsp 740968, Relator: Ministro ALDIR PASSARINHO JUNIOR, Data de Julgamento: 11/9/2007, T4 - QUARTA TURMA.

BRASIL. Superior Tribunal de Justiça - Resp 750735 , Relator: Ministro ALDIR PASSARINHO JUNIOR, Data de Julgamento: 4/6/2009, T4 - QUARTA TURMA.

BRASIL. Superior Tribunal de Justiça - REsp:

1105974 BA 2008/0260489-7, Relator: Ministro SIDNEI BENETI, Data de Julgamento: 23/4/2009, T3 - TERCEIRA TURMA, Data de Publicação: DJe $13 / 5 / 2009$

BRASIL. Superior Tribunal de Justiça - REsp: 856360 AC 2006/0118205-0, Relator: Ministra ELIANA CALMON, Data de Julgamento: 19/8/2008, T2 - SEGUNDA TURMA, Data de Publicação: DJe 23/9/2008.

BRASIL. Superior Tribunal de Justiça - REsp: 742137 RJ 2005/0060295-2, Relator: Ministra NANCY ANDRIGHI, Data de Julgamento: 21/8/2007, T3 - TERCEIRA TURMA, Data de Publicação: DJ 29/10/2007. p.218.

BRASIL. Superior Tribunal de Justiça - REsp: 856360 AC 2006/0118205-0, Relator: Ministra ELIANA CALMON, Data de Julgamento: 19/8/2008, T2 - SEGUNDA TURMA, Data de Publicação: DJe 23/9/2008.

BRASIL. Superior Tribunal de Justiça - REsp: 1074251 SP 2008/0141463-3, Relator: Ministro SIDNEI BENETI, Data de Julgamento: 23/4/2009, T3 - TERCEIRA TURMA, Data de Publicação: DJe $15 / 5 / 2009$.

BRASIL. Superior Tribunal de Justiça - AgRg no Ag 853854 RJ, Rel. Ministra DENISE ARRUDA, PRIMEIRA TURMA, julgado em 5/6/2007, DJ 29/06/2007. p.504.

BRASIL. Superior Tribunal de Justiça - REsp 1060856 RJ, Relator: Ministro HUMBERTO MARTINS, Data de Julgamento: 23/6/2009, T2 - SEGUNDA TURMA.
BRASIL. Superior Tribunal de Justiça - REsp 401358 PB, Relator: Ministro CARLOS FERNANDO MATHIAS, Data de Julgamento: 5/3/2009, T2 - QUARTA TURMA.

BRASIL. Superior Tribunal de Justiça - Resp 872630 , Relator: Ministro FRANCISCO FALCÃO, Data de Julgamento: 13/11/2007, T1 - PRIMEIRA TURMA.

CAHALI, Yussef Said. Dano Moral. 3.ed. ver., ampl. e atual. Conforme o Código Civil de 2002. São Paulo: Revista dos Tribunais, 2005.

CERQUEIRA, Naiara Guimarães de. Disciplina jurídica dos punitive damages no ordenamento jurídico brasileiro. Disponível em: <http:// www.revistas.unifacs.br/index.php/redu/article/ viewFile/1395/1082>. Acesso em: 22 abr. 2014.

DELGADO, Rodrigo Mendes. 0 valor do dano moral: como chegar até ele. 3.ed. Leme: J.H. Mizuno, 2011.

\section{DINIZ, Maria Helena. Curso de Direito Civil}

Brasileiro: Responsabilidade Civil, v.7. 21.ed. rev. e atual. De acordo com a reforma do CPC - São Paulo: Saraiva, 2007.

GONÇALVES, Carlos Roberto. Direito Civil Brasileiro: Responsabilidade Civil, v.4. 5.ed. São Paulo: Saraiva, 2010.

JOÃO, Mayana Barros Jorge. Punitive damages ou teoria do valor do desestímulo - análise crítica da sua aplicação no direito brasileiro. Disponível em: <http://www.ambito-juridico.com.br/site/?n_ link=revista_artigos_leitura\&artigo_id=13550>. Acesso em: 20 abri 2014.

MENDES, Robinson Bogue. Dano moral e obrigação de indenizar: critérios de fixação do quantum. Campo Grande: UCDB, 2000.

OLIVEIRA, Daniele Ulguim. Pressupostos da

Responsabilidade Civil. Disponível em: <http:// 
www.administradores.com.br/artigos/negocios/ pressupostos-da-responsabilidade-civil/26381/ >. Acesso em: 21 abr. 2014.

REIS, Júlia. 0 sistema de responsabilidade civil brasileiro e a teoria dos punitive damages.

Disponivel em: <http://www.edisonsiqueira.com.br/ site/doutrinas-detalhes.php?id=130>. Acesso em: 21 abr. 2014.

\section{SANTA CATARINA. AC 20120407380 SC,}

2012.040738-0 (Acórdão), Relator(a): Saul Steil, Julgamento: 13/8/2012, Órgão Julgador: Terceira Câmara de Direito Civil Julgado.
SANTOS, Pablo de Paula Saul. Responsabilidade civil: origem e pressupostos gerais. Disponível em: http://www.ambito-juridico.com.br/site/index. php/?n_link=revista_artigos_leitura\&artigo_ id=11875> Acesso em: 21 abr. 2014.

SANTOS, Antonio Jeová. Dano moral indenizável. 4.ed. rev., ampl. e atual. de acordo com o novo Código Civil. São Paulo: Revista dos Tribunais, 2003.

\section{VENOSA, Sílvio de Sávio. Direito Civil:}

Responsabilidade Civil. v.4. 10.ed. São Paulo: Atlas, 2010. 